\title{
Epidemiological factors associated with recent HIV infection among newly- diagnosed cases in Singapore, 2013-2017
}

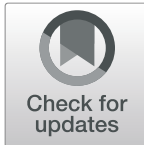

Li Wei Ang ${ }^{1 *}$, Carmen Low ${ }^{2 \dagger}$, Chen Seong Wong ${ }^{3,4,5}$, Irving Charles Boudville ${ }^{1}$, Matthias Paul Han Sim Toh ${ }^{1,6}$, Sophia Archuleta ${ }^{3,5,7}$, Vernon Jian Ming Lee ${ }^{6,8}$, Yee Sin Leo ${ }^{4,5,6,9,10}$, Angela Chow ${ }^{1,6,10,11}$ and Raymond Tzer-Pin Lin $2,5,12$

\begin{abstract}
Background: Early diagnosis is crucial in securing optimal outcomes in the HIV care cascade. Recent HIV infection $(\mathrm{RHI})$ serves as an indicator of early detection in the course of HIV infection. Surveillance of RHI is important in uncovering at-risk groups in which HIV transmission is ongoing. The study objectives are to estimate the proportion of RHI among persons newly-diagnosed in 2013-2017, and to elucidate epidemiological factors associated with RHI in Singapore.
\end{abstract}

Methods: As part of the National HIV Molecular Surveillance Programme, residual plasma samples of treatmentnaïve HIV-1 positive individuals were tested using the biotinylated peptide-capture enzyme immunoassay with a cutoff of normalized optical density $\leq 0.8$ for evidence of $\mathrm{RH}$. A recent infection testing algorithm was applied for the classification of RHI. We identified risk factors associated with $\mathrm{RHI}$ using logistic regression analyses.

Results: A total of 701 newly-diagnosed HIV-infected persons were included in the study. The median age at HIV diagnosis was 38 years (interquartile range, 28-51). The majority were men (94.2\%), and sexual route was the predominant mode of HIV transmission (98.3\%). Overall, 133/701 (19.0, 95\% confidence interval [CI] 16.2-22.0\%) were classified as RHI. The proportions of RHI in 2015 (31.1\%) and 2017 (31.0\%) were significantly higher than in 2014 (11.2\%). A significantly higher proportion of men having sex with men (23.4, 95\% Cl 19.6-27.6\%) had RHI compared with heterosexual men $(11.1,95 \% \mathrm{Cl} 7.6-15.9 \%)$. Independent factors associated with RHI were: age 1524 years (adjusted odds ratio [aOR] 4.18, 95\% Cl 1.69-10.31) compared with $\geq 55$ years; HIV diagnosis in 2015 (aOR $2.36,95 \% \mathrm{Cl} 1.25-4.46$ ) and 2017 (aOR 2.52, 95\% Cl 1.32-4.80) compared with 2013-2014; detection via voluntary testing (aOR 1.91, 95\% Cl 1.07-3.43) compared with medical care; and self-reported history of HIV test(s) prior to diagnosis (aOR 1.72, 95\% Cl 1.06-2.81).

Conclusion: Although there appears to be an increasing trend towards early diagnosis, persons with RHI remain a minority in Singapore. The strong associations observed between modifiable behaviors (voluntary testing and HIV testing history) and RHI highlight the importance of increasing the accessibility to HIV testing for at-risk groups.

Keywords: Recent HIV infection, Newly diagnosed, Epidemiology, Risk factors, HIV testing, Modifiable behaviors

\footnotetext{
*Correspondence: Li_Wei_Ang@ncid.sg

${ }^{+}$Li Wei Ang and Carmen Low contributed equally to this work.

${ }^{1}$ National Public Health and Epidemiology Unit, National Centre for Infectious

Diseases, 16 Jalan Tan Tock Seng, Singapore 308442, Singapore

Full list of author information is available at the end of the article
}

(c) The Author(s). 2021 Open Access This article is licensed under a Creative Commons Attribution 4.0 International License, which permits use, sharing, adaptation, distribution and reproduction in any medium or format, as long as you give appropriate credit to the original author(s) and the source, provide a link to the Creative Commons licence, and indicate if changes were made. The images or other third party material in this article are included in the article's Creative Commons licence, unless indicated otherwise in a credit line to the material. If material is not included in the article's Creative Commons licence and your intended use is not permitted by statutory regulation or exceeds the permitted use, you will need to obtain permission directly from the copyright holder. To view a copy of this licence, visit http://creativecommons.org/licenses/by/4.0/ The Creative Commons Public Domain Dedication waiver (http://creativecommons.org/publicdomain/zero/1.0/) applies to the data made available in this article, unless otherwise stated in a credit line to the data. 


\section{Introduction}

Knowledge of HIV serostatus is an important element of HIV prevention and treatment efforts. Early diagnosis enhances the effectiveness of all subsequent steps in the cascade of HIV care, including initiation of combination antiretroviral therapy (ART) in the early phase of infection [1]. Immediate treatment is recommended for all HIV patients with detectable viremia regardless of CD4 count for better prognosis, and to reduce HIV transmission at the population level [2-4].

In Singapore, a cumulative total of 7982 HIV-infected Singapore residents had been notified to the National HIV Registry as of end-2017 [5]. The annual number of HIV notifications remained stable at an average of 450 in 20072017. The proportion of women diagnosed with HIV in Singapore was extremely low at $10 \%$ or less, in stark contrast to that of the Southeast Asian region where women constituted $37 \%$ of HIV diagnoses [6]. Sexual transmission accounted for $97 \%$ of all notifications. There were about 6900 (95\% confidence interval [CI] 6650-7050) persons living with HIV in Singapore as of end-2014, and among them, 71.7\% (95\% CI 70.0-74.2\%) had been diagnosed [7].

Despite the availability of effective highly active ART since 1996, a local study found that $54 \%$ of persons newlydiagnosed with HIV in 1996-2009 had late presentation to care, defined as having either a CD4 T-helper lymphocyte count (CD4 count) $<200$ cells $/ \mathrm{mm}^{3}$ at the time of presentation to care, or AIDS-defining conditions within 1 year of HIV diagnosis [8]. However, there are varying definitions for late diagnosis, which limits the comparability between studies $[9,10]$. Some studies used a combination of laboratorybased definitions, such as CD4 count $<200$ cells $/ \mathrm{mm}^{3}$ [11] or $<350$ cells $/ \mathrm{mm}^{3}$ [12], and a clinical definition based on the occurrence of an AIDS-defining event in 3 months [11], 6 months [12, 13] or 1 year [14, 15] following HIV diagnosis. Although these definitions indicate the stage of disease progression at the time of diagnosis in relation to the optimal time for commencement of treatment, they do not constitute a direct measure of time from HIV infection [16].

Recent HIV infection (RHI) classification can be used as an indicator for early diagnosis, as recent infection generally refers to the phase up to 6 months after acute infection during which detectable anti-HIV-1 antibodies develop [17]. RHI implies ongoing transmission, and ascertainment of current HIV transmission patterns provides insights to guide preventive and interventional strategies targeted at high-risk individuals. The aims of this retrospective study were to estimate the proportion of RHI and elucidate epidemiological factors associated with RHI in Singapore.

\section{Methods}

\section{Study population}

HIV is a legally notifiable disease in Singapore. The HIV notification system is supplemented with additional information obtained through review of medical case notes and interviews with the cases. The information collected on all HIV cases includes socio-demographic characteristics, the first CD4 count, mode of detection and exposure factors.

To better monitor the dynamics of HIV transmission in Singapore, the National Public Health Laboratory (NPHL) commenced detection of RHI on residual plasma samples from HIV cases since 2013, as part of the National HIV Molecular Surveillance Programme under the Infectious Diseases Act (IDA) [18]. The proportion of RHI in newly-diagnosed HIV cases can be estimated using serological assays to measure the level of HIV-1-specific antibodies out of total immunoglobulin (IgG), which increases with time since infection $[19,20]$. To further increase the specificity of the result, a recent infection testing algorithm (RITA), taking CD4 counts and supplementary clinical information into consideration to classify an HIV infection as recent or long-term, was applied as recommended by the World Health Organization (WHO) guidelines [21]. The main advantage of such an approach in determining the evidence of RHI is that a single sample can be taken at the time of HIV diagnosis without the need for follow-up, unlike with cohort studies.

Test results from NPHL were linked to the National HIV Registry using unique personal identifiers tagged to the samples. Personal identifiers were permanently removed from the merged database prior to statistical analysis.

Residual plasma samples of individuals whose HIV infection had been confirmed by Western blot assay were collected from public acute-care tertiary hospitals for the National HIV Molecular Surveillance Programme. We excluded HIV cases notified to the National HIV Registry from this study if they met one or more of the following criteria: unavailability of CD4 count at diagnosis; presence of an AIDS-defining illness at the time of diagnosis; commencement of ART prior to specimen collection. The testing for RHI was confined to plasma samples drawn from treatment-naïve individuals within 12 months of HIV diagnosis in 2013-2017.

\section{Laboratory methods}

The biotinylated peptide-capture enzyme immunoassay (BED-CEIA) assay (Sedia Biosciences Corp, Portland, USA) was performed according to the manufacturer's instructions on frozen residual plasma [22]. This assay measures the proportion of HIV-1 specific immunoglobulin (IgG) relative to total IgG against an internal calibrator specimen. It detects increasing proportion of HIV-1 IgG following seroconversion [23, 24].

Briefly, human antibodies including HIV-specific antibodies were captured in the solid phase of the microplate. After incubation $\left(60 \mathrm{~min}, 37^{\circ} \mathrm{C}\right)$ and washing, the 
custom biotinylated peptide (BED) that includes divergent immunodominant gp41 sequences from all HIV-1 (group M) subtypes and recombinants, was added (60 min, $37^{\circ} \mathrm{C}$ ). After washing, the plate was incubated for 90 min with streptavidin-peroxidase. Following another around of washes, tetramethylbenzidine (TMB) was added for $15 \mathrm{~min}$ at room temperature. The reaction was stopped by the addition of a stopping solution $(1 \mathrm{~N}$ sulfuric acid) and the optical density (OD) was read at 450 $\mathrm{nm}$ with a spectrophotometer.

Results were reported as normalized OD (OD-n) units, calculated by dividing the $\mathrm{OD}$ value of sample or median OD of controls by the median OD of the calibrator. All samples with OD- $\mathrm{n} \leq 1.2$ were tested in triplicates to confirm whether it was a recent or long-term infection. A final OD-n cut-off of $<0.8$ was used to distinguish recent from long-term infection. This threshold corresponds to a mean recency period of 197 days (95\% confidence interval [CI] 173-220) [19]. We applied RITA to individuals whose samples returned results indicating evidence of RHI. Individuals were reclassified as having non-RHI (NRHI) if they had CD4 count $<200$ cells $/ \mathrm{mm}^{3}$ [25].

\section{Statistical analysis}

We calculated the 95\% CI for binomial proportions using Wilson's method. We compared individuals with RHI and those with NRHI using the Chi-square test or Fisher's exact test for categorical variables, and MannWhitney $\mathrm{U}$ test for continuous variables.

The main outcome was whether an individual had RHI or NRHI. Crude and adjusted odds ratio were calculated using logistic regression analyses. Multivariable analysis was used to determine independent factors for RHI. Variables with $p<0.10$ from univariable regression analyses were entered as initial candidates using backward stepwise selection process, and covariates with $p<$ 0.05 were retained in the final multivariable model.

For variables with missing data proportion less than $30 \%$, we used missForest package (version 1.4) of $\mathrm{R}$, an iterative non-parametric method, to impute the missing values. This random forest-based method produces a single imputed dataset without setting aside test data or performing cross validations [26]. The proportion of missing data ranged from 0.4 to $8.4 \%$. Sensitivity analyses were performed to assess the robustness of our findings by using listwise deletion for missing data of independent variables in the multivariable logistic regression model. We also inserted an "unknown" category for variables with missing data when determining the independent risk factors associated with RHI.

All $p$ values reported were 2 -sided and statistical significance was taken as $p<0.05$. Statistical analyses were performed using $\mathrm{R}$ version 3.6.1 ( $\mathrm{R}$ Foundation for
Statistical Computing, Vienna, Austria) and Stata version 16 (StataCorp, College Station, TX).

\section{Results}

NPHL collected 711 samples for the National HIV Molecular Surveillance Programme, of which 10 (1.4\%) did not meet the inclusion criteria for this study (Fig. 1). A total of 701 newly-diagnosed HIV-infected individuals were included in the analysis, and they constituted $31.8 \%$ of all HIV cases notified to the National HIV Registry in 2013-2017.

\section{Characteristics of study population}

The median age at HIV diagnosis was 38 years (interquartile range [IQR], 28-51). The majority of the study population were male $(94.2 \%)$, Chinese $(72.0 \%)$, had never been married (72.8\%), had attained education at post-secondary level $(75.3 \%)$, and worked in professional/managerial positions or administrative/serviceoriented sectors $(62.6 \%)$ (Table 1$)$. The main reasons for the current HIV test were medical care (38.1\%), routine programmatic screening (31.8\%), and voluntary testing (23.3\%). Three in five newly-diagnosed HIV infections were attributed to homosexual/bisexual transmission (61.6\%), and another $36.7 \%$ were accounted for by heterosexual contact. About half (52.5\%) of the cases had undergone HIV test(s) prior to their diagnosis. Over two-thirds (65.0\%) reported having regular and casual contacts only as sexual partners.

The socio-demographic and epidemiological characteristics of the 701 newly-diagnosed HIV-positive individuals in our study were broadly similar to the 2207 cases notified to the National HIV Registry during the fiveyear period (Table 1). There might have been an overrepresentation of HIV-positive individuals who acquired infection through sexual contact among men having sex with men (MSM) in our study (61.6\%), when compared with that of all HIV notifications (56.2\%).

\section{Proportion of recent HIV infection}

Of the 701 residual plasma samples tested, 180 (25.7\%) were initially classified as recently infected by reactivity on the BED-CEIA. Of these 180 individuals, 47 had low CD4 count $\left(<200\right.$ cells $\left./ \mathrm{mm}^{3}\right)$ and they were therefore reclassified as having long-term infection according to RITA, leaving 133 individuals classified as recently infected (Fig. 1). None of these 133 individuals had an AIDS-defining illness at diagnosis, hence no further reclassification was needed. Overall, about one-fifth (19.0, 95\% CI 16.2-22.0\%) of the newly-diagnosed, treatmentnaïve HIV-positive individuals had RHI.

The proportions of RHI in 2015 (31.1\%) and 2017 (31.0\%) were significantly higher than in $2014(11.2 \%)(p<$ 0.01) (Fig. 2). Over the five-year study period, a 


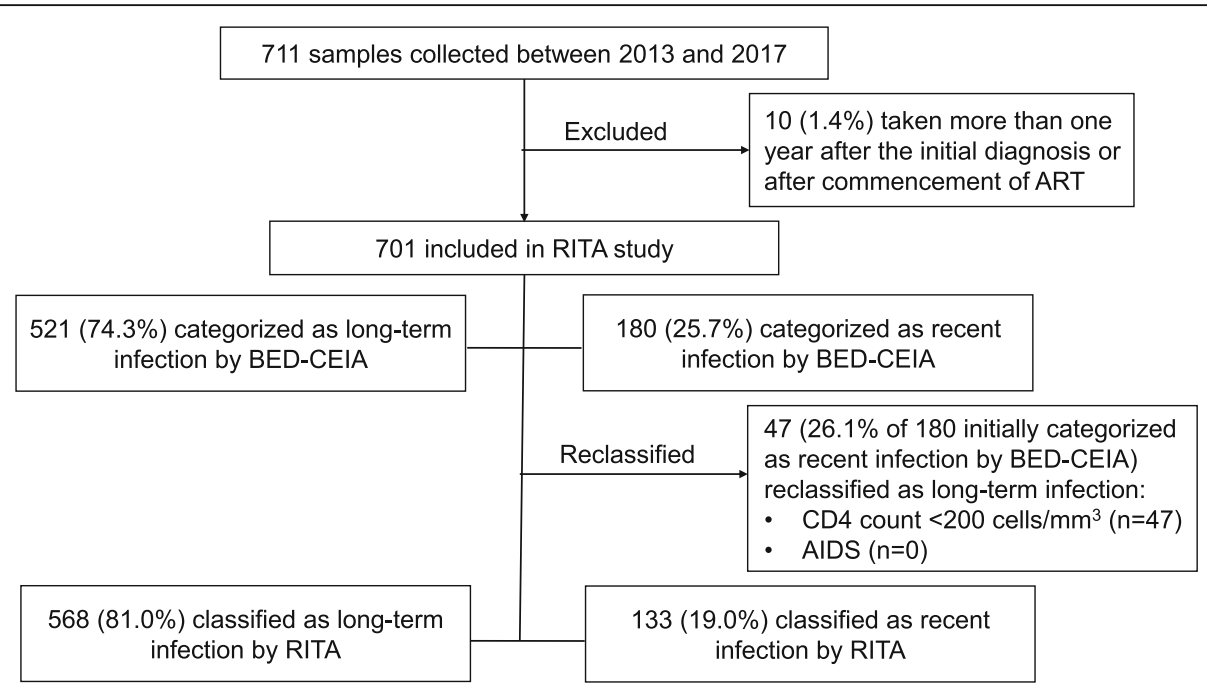

Fig. 1 Flowchart of samples included in analyses and classified according to the recent infection testing algorithm (RTA), 2013-2017. ART: antiretroviral therapy

significantly higher proportion of MSM (23.4, 95\% CI 19.6-27.6\%) had RHI compared with heterosexual men (11.1, 95\% CI 7.6-15.9\%). Stratification by year of HIV diagnosis revealed significant differences between these two exposure risk groups in 2016 and 2017 (Fig. 3).

\section{Factors associated with recent HIV infection}

Recently infected individuals were younger than those with long-term infection; the median age was 32 years (IQR 24-44) in cases with RHI and 36 years (IQR 29$52)$ among those with NRHI $(p<0.0005)$. Individuals aged 15-24 at HIV diagnosis constituted a significantly higher proportion of those with RHI, when compared with NRHI (25.6\% vs $10.9 \%$ ), whereas those aged $\geq 55$ years made up a lower proportion (6.0\% vs $19.2 \%)$ (Table $1)$. A significantly higher proportion of individuals classified as having RHI were never married (87.2\% vs $69.4 \%)$, diagnosed in later years of $2015-2017$ (87.2\% vs 73.9\%), detected via voluntary testing (33.8\% vs $20.8 \%)$, infected via homosexual/bisexual mode of transmission $(75.9 \%$ vs $58.3 \%$ ), and had history of HIV test(s) prior to diagnosis (69.2\% vs $48.6 \%)$.

Univariable logistic regression analyses revealed that age group, marital status, year of diagnosis, reasons for current HIV test, mode of HIV transmission and whether the individual had been tested for HIV prior to positive HIV diagnosis were epidemiological factors associated with RHI (Table 2).

On multivariable logistic regression analysis, risk factors independently associated with RHI were: age 15-24 years (adjusted odds ratio [aOR] 4.18, 95\% CI 1.6910.31) compared with those $\geq 55$ years, HIV diagnosis in 2015 (aOR 2.36, 95\% CI 1.25-4.46) and 2017 (aOR 2.52, 95\% CI 1.32-4.80) compared with 2013-2014, detection via voluntary testing (aOR 1.91, 95\% CI 1.07-3.43) compared with routine medical care, and self-reported history of HIV testing prior to diagnosis (aOR 1.72, 95\% CI 1.06-2.81) (Table 2).

We obtained similar results (not shown) when an "unknown" category was included for variables with missing data in the multivariable logistic regression model. In complete case analysis, detection via voluntary testing was no longer statistically significant $(p=0.078)$ in the multivariable model.

\section{Discussion}

Among newly-diagnosed HIV-positive individuals who had yet to receive ART, nearly one-fifth had acquired their HIV infection within 6 months of diagnosis. We found that the majority of HIV-infected persons were diagnosed later in the course of the disease, which underlines the problem of delayed HIV diagnosis in Singapore. The annual proportion of late presentation among all newly-diagnosed cases notified to the National HIV Registry has remained considerably high, ranging from 40.4 to $48.7 \%$ in $2013-2017$.

The overall proportion of RHI among newly-diagnosed HIV cases in our study (19.0\%) was lower than that of Tokyo, Japan (38.6\%) [27], Taiwan (43.8\%) [28], and Australia (25.0\% in 2017) [29] (Table S1). In Europe, the estimated proportion of RHI ranged from 14.7 to $47.3 \%$ in developed countries [16,30-38], based on one of the three assays (avidity index assay, detuned assay and BED assay) in different time periods (Table S1). In the United States, 20\% of patients newly-diagnosed with HIV in 1997-2001 had acquired their infection within 6 months of diagnosis [39]. We found serological evidence of RHI in $23.4 \%$ of newlydiagnosed HIV-positive MSM, which was lower than that of 
Table 1 Characteristics (\%) of newly-diagnosed HIV-positive individuals included in the RITA study, and all cases notified to the National HIV Registry, 2013-2017

\begin{tabular}{|c|c|c|c|c|c|}
\hline \multirow[t]{2}{*}{ Characteristic } & \multirow{2}{*}{$\begin{array}{l}\text { All HIV } \\
\text { notifications } \\
(N=2207) \\
\text { n (\%) }\end{array}$} & \multicolumn{4}{|c|}{ Included in RITA study } \\
\hline & & $\begin{array}{l}\text { Total }(N=701) \\
\mathrm{n}(\%)\end{array}$ & $\begin{array}{l}\mathrm{RHI}(N=133) \\
\mathrm{n}(\%)\end{array}$ & $\begin{array}{l}\text { NRHI }(N=568) \\
\text { n (\%) }\end{array}$ & $\begin{array}{l}P \text { - } \\
\text { value§ }\end{array}$ \\
\hline Age at HIV diagnosis (years) & & & & & $<0.0005$ \\
\hline $0-14$ & $2(0.1)$ & $0(0.0)$ & $0(0.0)$ & $0(0.0)$ & \\
\hline $15-24$ & $220(10.0)$ & $96(13.7)$ & $34(25.6)$ & $62(10.9)$ & \\
\hline $25-34$ & $535(24.2)$ & $186(26.5)$ & $40(30.1)$ & $146(25.7)$ & \\
\hline $35-44$ & $572(25.9)$ & $157(22.4)$ & $30(22.6)$ & $127(22.4)$ & \\
\hline $45-54$ & $492(22.3)$ & $145(20.7)$ & $21(15.8)$ & $124(21.8)$ & \\
\hline $55-64$ & $285(12.9)$ & $87(12.4)$ & $7(5.3)$ & $80(14.1)$ & \\
\hline$\geq 65$ & $101(4.6)$ & $30(4.3)$ & $1(0.8)$ & $29(5.1)$ & \\
\hline Gender & & & & & 0.840 \\
\hline Male & $2061(93.4)$ & $660(94.2)$ & $126(94.7)$ & $534(94.0)$ & \\
\hline Female & $146(6.6)$ & $41(5.8)$ & $7(5.3)$ & $34(6.0)$ & \\
\hline Ethnic group & & & & & 0.695 \\
\hline Chinese & $1538(69.7)$ & $505(72.0)$ & $97(72.9)$ & $408(71.8)$ & \\
\hline Malay & $426(19.3)$ & $135(19.3)$ & $22(16.5)$ & $113(19.9)$ & \\
\hline Indian & $141(6.4)$ & $41(5.8)$ & $10(7.5)$ & $31(5.5)$ & \\
\hline Others & $102(4.6)$ & $20(2.9)$ & $4(3.0)$ & $16(2.8)$ & \\
\hline Marital status & & & & & $<0.0005$ \\
\hline Never married & $1522(69.0)$ & $510(72.8)$ & $116(87.2)$ & $394(69.4)$ & \\
\hline Married & $472(21.4)$ & $125(17.8)$ & $15(11.3)$ & $110(19.4)$ & \\
\hline Separated/Divorced/Widowed & $213(9.7)$ & $66(9.4)$ & $2(1.5)$ & $64(11.3)$ & \\
\hline Educational level & & & & & 0.139 \\
\hline No formal /Primary & $124(5.6)$ & $36(5.1)$ & $4(3.0)$ & $32(5.6)$ & \\
\hline Secondary & $185(8.4)$ & $46(6.6)$ & $12(9.0)$ & $34(6.0)$ & \\
\hline Post-secondary & $1617(73.3)$ & $528(75.3)$ & $93(69.9)$ & $435(76.6)$ & \\
\hline Tertiary & $273(12.4)$ & $88(12.6)$ & $23(17.3)$ & $65(11.4)$ & \\
\hline Unknown & $8(0.4)$ & $3(0.4)$ & $1(0.8)$ & $2(0.4)$ & \\
\hline Occupational type & & & & & 0.048 \\
\hline Professional/executive & $436(19.8)$ & $123(17.5)$ & $25(18.8)$ & $98(17.3)$ & \\
\hline Administrative/service-oriented & $888(40.2)$ & $316(45.1)$ & $62(46.6)$ & $254(44.7)$ & \\
\hline Blue-collar worker & $275(12.5)$ & $98(14.0)$ & $13(9.8)$ & $85(15.0)$ & \\
\hline Unemployed & $80(3.6)$ & $16(2.3)$ & $0(0.0)$ & $16(2.8)$ & \\
\hline Others & $290(13.1)$ & $101(14.4)$ & $27(20.3)$ & $74(13.0)$ & \\
\hline Unknown & $238(10.8)$ & $47(6.7)$ & $6(4.5)$ & $41(7.2)$ & \\
\hline Year of HIV diagnosis & & & & & 0.009 \\
\hline 2013 & $454(20.6)$ & $49(7.0)$ & $4(3.0)$ & $45(7.9)$ & \\
\hline 2014 & $456(20.7)$ & $116(16.5)$ & $13(9.8)$ & $103(18.1)$ & \\
\hline 2015 & $455(20.6)$ & $166(23.7)$ & $40(30.1)$ & $126(22.2)$ & \\
\hline 2016 & $408(18.5)$ & $214(30.5)$ & $39(29.3)$ & $175(30.8)$ & \\
\hline 2017 & $434(19.7)$ & $156(22.3)$ & $37(27.8)$ & $119(21.0)$ & \\
\hline Reason for HIV testing & & & & & $<0.0005$ \\
\hline Medical care & $1046(47.4)$ & $267(38.1)$ & $27(20.3)$ & $240(42.3)$ & \\
\hline
\end{tabular}


Table 1 Characteristics (\%) of newly-diagnosed HIV-positive individuals included in the RITA study, and all cases notified to the National HIV Registry, 2013-2017 (Continued)

\begin{tabular}{|c|c|c|c|c|c|}
\hline \multirow[t]{2}{*}{ Characteristic } & \multirow{2}{*}{$\begin{array}{l}\text { All HIV } \\
\text { notifications } \\
(N=2207) \\
\text { n (\%) }\end{array}$} & \multicolumn{4}{|c|}{ Included in RITA study } \\
\hline & & $\begin{array}{l}\text { Total }(N=701) \\
\mathrm{n}(\%)\end{array}$ & $\begin{array}{l}\mathrm{RHI}(N=133) \\
\mathrm{n}(\%)\end{array}$ & $\begin{array}{l}\text { NRHI }(N=568) \\
\mathrm{n}(\%)\end{array}$ & $\begin{array}{l}P \text { - } \\
\text { value§ }\end{array}$ \\
\hline Voluntary testing & $432(19.6)$ & $163(23.3)$ & $45(33.8)$ & $118(20.8)$ & \\
\hline Routine programmatic screening $†$ & $587(26.6)$ & $223(31.8)$ & $51(38.3)$ & $172(30.3)$ & \\
\hline Others & $142(6.4)$ & $48(6.8)$ & $10(7.5)$ & $38(6.7)$ & \\
\hline Mode of HIV transmission & & & & & 0.002 \\
\hline Heterosexual & $881(39.9)$ & $257(36.7)$ & $31(23.3)$ & $226(39.8)$ & \\
\hline Homosexual/bisexual & $1241(56.2)$ & $432(61.6)$ & $101(75.9)$ & $331(58.3)$ & \\
\hline IDU & $13(0.6)$ & $2(0.3)$ & $0(0.0)$ & $2(0.4)$ & \\
\hline Others & $9(0.4)$ & $1(0.1)$ & $0(0.0)$ & $1(0.2)$ & \\
\hline Unknown & $63(2.9)$ & $9(1.3)$ & $1(0.8)$ & $8(1.4)$ & \\
\hline Ever tested for HIV prior to positive diagnosis & & & & & $<0.0005$ \\
\hline Yes & $1084(49.1)$ & $368(52.5)$ & $92(69.2)$ & $276(48.6)$ & \\
\hline No & 837 (37.9) & $274(39.1)$ & $31(23.3)$ & $243(42.8)$ & \\
\hline Unknown & $286(13.0)$ & $59(8.4)$ & $10(7.5)$ & $49(8.6)$ & \\
\hline Type of sexual partners & & & & & 0.056 \\
\hline Regular only & $236(10.7)$ & $61(8.7)$ & $11(8.3)$ & $50(8.8)$ & \\
\hline Regular \& casual only & $1347(61.0)$ & $456(65.0)$ & $99(74.4)$ & $357(62.9)$ & \\
\hline Sex workers \& social escorts & $542(24.6)$ & $170(24.3)$ & $22(16.5)$ & $148(26.1)$ & \\
\hline Unknown & $82(3.7)$ & $14(2.0)$ & $1(0.8)$ & $13(2.3)$ & \\
\hline
\end{tabular}

RHI Recent HIV infection, NRHI Non-recent HIV infection, RITA Recent infection testing algorithm; IDU Intravenous drug use

† Routine programmatic HIV screening includes screening programmes for persons with sexually transmitted infections, hospital inpatients and those identified

through contact tracing

$\S P$-value is for the comparison between $\mathrm{RHI}$ group $(N=133)$ and $\mathrm{NRHI}$ group $(N=568)$

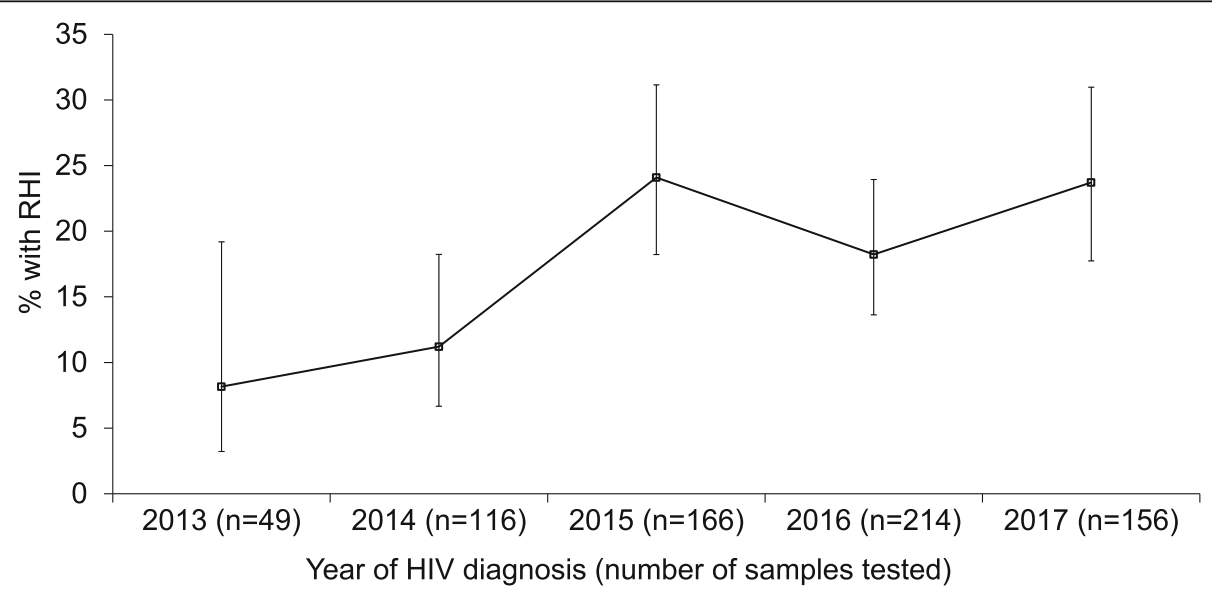

Fig. 2 Proportion of recent HIV infection among newly-diagnosed HIV-positive individuals included in the RITA study, 2013-2017. The error bars indicate $95 \%$ confidence interval 


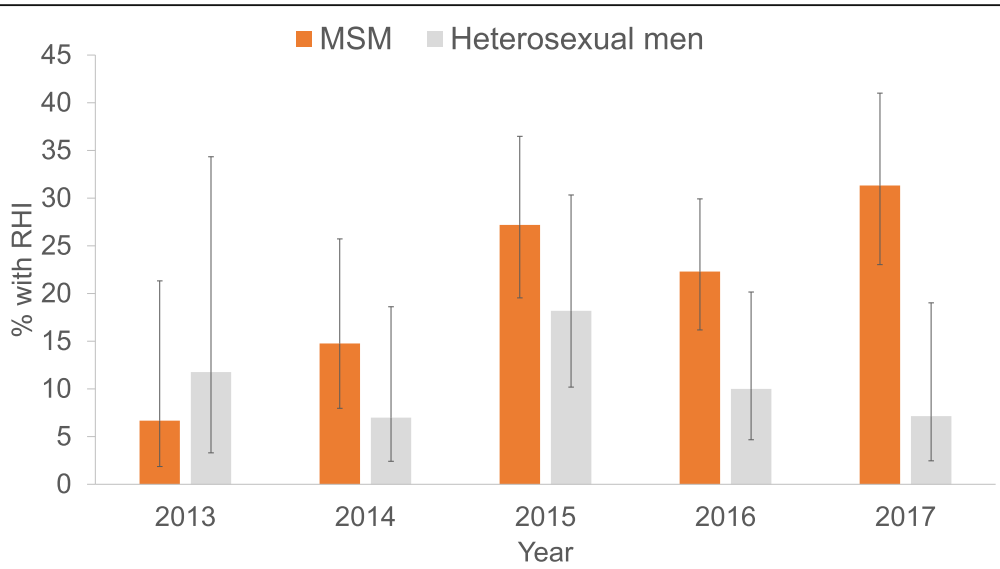

Fig. 3 Proportion of recent HIV infection among newly-diagnosed HIV-positive men who had sex with men (MSM) and men infected with HIV via heterosexual transmission included in the RITA study, 2013-2017. The error bars indicate 95\% confidence interval

China (41.9\%) [40] and the state of Victoria, Australia (35.8\%) [41]. However, some caution should be exercised in the interpretation and comparison of the proportion of RHI, as it largely depends on testing patterns of the at-risk population and underlying pattern of HIV incidence [30].

A higher proportion of RHI implies either a higher frequency of HIV testing and/or HIV incidence in certain risk groups. In this study, we observed higher overall proportions of RHI in 2015 and 2017 (Fig. 2), which corresponded to the trend observed in MSM (Fig. 3). The overall proportion of RHI among HIV-infected MSM (23.4\%) was double that of men infected with HIV via heterosexual transmission (11.1\%). This is corroborated by the national notification data in which a significantly higher proportion of late presenters were among cases who acquired HIV infection through heterosexual contact compared with those infected via MSM contact [8]. MSM in Singapore are known to undergo more frequent HIV testing, possibly due to their recognition of the importance of regular screening and/or an indication that they are at higher risk of infection after a risk exposure. These are potentially the result of ongoing targeted sexual health messaging campaigns in the country. An outreach HIV testing project conducted by Action for AIDS (AfA), a local non-governmental HIV/AIDS communitybased organization, at venues frequented by MSM in Singapore found that there were fewer first-time testers in 2013 than in previous years, and about half of the MSM had been tested in the 12 months prior to the survey [42]. The proportion of RHI among newly-diagnosed HIV-positive MSM had also increased in the United Kingdom [43] and Germany [44].

Independent risk factors associated with RHI identified in studies conducted in many European countries [16, 30, 35-38], and the United States [39] include younger age, MSM, high economic status, those who underwent testing after a risk exposure, higher frequency of HIV testing, more sexual partners and history of diagnosis of sexually transmitted infections (STIs) (Table S1). In our study, younger age, HIV diagnosis in more recent years, detection via voluntary testing, and history of HIV test(s) prior to positive diagnosis were independent factors associated with RHI (Table 2).

Compared with newly-diagnosed HIV-positive individuals aged $\geq 55$ years, those aged $15-24$ years were more likely to have been infected recently. The proportion of RHI declined with age, from $35.4 \%$ in newly-diagnosed cases aged $15-24$ years to $6.8 \%$ in those aged $\geq 55$ years $(p<0.0005)$ (Table 2). On the other hand, the proportion of late presentation among HIV cases is known to increase with age [8]. Data from AfA's anonymous testing and counselling service indicated that the majority of clients who get tested are 20-39 years of age (81\%) [45], suggesting more frequent HIV testing among younger adults than older individuals.

Detection via voluntary testing was an independent factor associated with higher likelihood of RHI. The decision to be voluntarily tested for HIV is usually based on awareness of testing benefits and perception of the risk of recent HIV exposure. A local study on male HIV cases infected via the sexual route and diagnosed in 1985-2007 found that MSM were more likely to undergo voluntary testing than heterosexual men [46].

Self-reported history of HIV testing prior to positive diagnosis was an independent factor for RHI. Our study revealed that previous HIV testing was reported in $69.2 \%$ of the cases with RHI, significantly higher than the $48.6 \%$ among those with NRHI (Table 1). This is to be expected, as a recent infection is more likely to be picked up among repeat testers and after a risk exposure. The number of lifetime HIV tests performed was strongly associated with RHI in studies conducted in 
Table 2 Proportion and odds ratios of factors for recent HIV infection among newly-diagnosed HIV-positive individuals included in the RITA study, 2013-2017

\begin{tabular}{|c|c|c|c|c|c|c|c|}
\hline \multirow[t]{2}{*}{ Characteristic } & \multirow{2}{*}{$\begin{array}{l}\% \\
\text { of } \\
\text { RHI }\end{array}$} & \multicolumn{3}{|c|}{ Univariable model } & \multicolumn{3}{|c|}{ Multivariable model $^{\mathrm{b}}$} \\
\hline & & COR & $(95 \% \mathrm{Cl})$ & $P$ value & aOR & $(95 \% \mathrm{Cl})$ & $P$ value \\
\hline \multicolumn{8}{|l|}{ Age at diagnosis (years) } \\
\hline $15-24$ & 35.4 & 7.47 & $(3.26-17.15)$ & $<0.0005$ & 4.18 & $(1.69-10.31)$ & 0.002 \\
\hline $25-34$ & 21.5 & 3.73 & $(1.68-8.30)$ & 0.001 & 2.19 & $(0.93-5.16)$ & 0.073 \\
\hline $35-44$ & 19.1 & 3.22 & $(1.42-7.31)$ & 0.005 & 2.01 & $(0.84-4.77)$ & 0.115 \\
\hline $45-54$ & 14.5 & 2.31 & $(0.98-5.42)$ & 0.055 & 1.83 & $(0.76-4.40)$ & 0.176 \\
\hline$\geq 55$ & 6.8 & 1.00 & Referent & & 1.00 & Referent & \\
\hline \multicolumn{8}{|l|}{ Gender } \\
\hline Male & 19.1 & 1.15 & $(0.50-2.64)$ & 0.749 & & & \\
\hline Female & 17.1 & 1.00 & Referent & & & & \\
\hline \multicolumn{8}{|l|}{ Ethnic group } \\
\hline Chinese & 19.2 & 1.00 & Referent & & & & \\
\hline Malay & 16.3 & 0.82 & $(0.49-1.36)$ & 0.440 & & & \\
\hline Indian \& others & 23.0 & 1.25 & $(0.66-2.37)$ & 0.488 & & & \\
\hline \multicolumn{8}{|l|}{ Marital status } \\
\hline Never married & 8.2 & 1.00 & Referent & & & & \\
\hline Married & 11.2 & 0.46 & $(0.26-0.83)$ & 0.009 & & & \\
\hline Separated/Divorced/Widowed & 24.1 & 0.11 & $(0.03-0.44)$ & 0.002 & & & \\
\hline \multicolumn{8}{|l|}{ Educational level $^{a}$} \\
\hline No formal/Primary & 11.1 & 1.00 & Referent & & & & \\
\hline Secondary & 26.1 & 2.82 & $(0.83-9.66)$ & 0.098 & & & \\
\hline Post-secondary & 17.7 & 1.72 & $(0.60-4.99)$ & 0.315 & & & \\
\hline Tertiary & 25.8 & 2.79 & $(0.89-8.74)$ & 0.079 & & & \\
\hline \multicolumn{8}{|l|}{ Occupational type ${ }^{a}$} \\
\hline Professional/executive & 20.2 & 1.00 & Referent & & & & \\
\hline Administrative/service-oriented & 19.5 & 0.96 & $(0.58-1.59)$ & 0.867 & & & \\
\hline Blue-collar worker & 12.3 & 0.55 & $(0.27-1.14)$ & 0.109 & & & \\
\hline Unemployed \& others & 22.0 & 1.12 & $(0.61-2.04)$ & 0.711 & & & \\
\hline \multicolumn{8}{|l|}{ Year of HIV diagnosis } \\
\hline 2013-2014 & 10.3 & 1.00 & Referent & & 1.00 & Referent & \\
\hline 2015 & 24.1 & 2.76 & $(1.49-5.11)$ & 0.001 & 2.36 & $(1.25-4.46)$ & 0.008 \\
\hline 2016 & 18.2 & 1.94 & $(1.05-3.57)$ & 0.033 & 1.69 & $(0.89-3.20)$ & 0.107 \\
\hline 2017 & 23.7 & 2.71 & $(1.45-5.05)$ & 0.002 & 2.52 & $(1.32-4.80)$ & 0.005 \\
\hline \multicolumn{8}{|l|}{ Reason for HIV testing } \\
\hline Medical care & 10.1 & 1.00 & Referent & & 1.00 & Referent & \\
\hline Voluntary testing & 27.6 & 3.39 & $(2.00-5.73)$ & $<0.0005$ & 1.91 & $(1.07-3.43)$ & 0.029 \\
\hline Routine programmatic screening ${ }^{c}$ & 22.9 & 2.64 & $(1.59-4.37)$ & $<0.0005$ & 1.62 & $(0.93-2.83)$ & 0.090 \\
\hline Others & 20.8 & 2.34 & $(1.05-5.22)$ & 0.038 & 1.79 & $(0.77-4.16)$ & 0.174 \\
\hline \multicolumn{8}{|l|}{ Mode of HIV transmission ${ }^{a}$} \\
\hline Heterosexual & 11.9 & 1.00 & Referent & & & & \\
\hline Homosexual/bisexual & 23.2 & 2.24 & $(1.45-3.46)$ & $<0.0005$ & & & \\
\hline IDU \& others & 25.0 & 2.47 & $(0.25-24.52)$ & 0.439 & & & \\
\hline
\end{tabular}

Ever tested for HIV prior to positive diagnosis ${ }^{a}$ 
Table 2 Proportion and odds ratios of factors for recent HIV infection among newly-diagnosed HIV-positive individuals included in the RITA study, 2013-2017 (Continued)

\begin{tabular}{|c|c|c|c|c|c|c|c|}
\hline \multirow[t]{2}{*}{ Characteristic } & \multirow{2}{*}{$\begin{array}{l}\% \% \\
\text { of } \\
\text { RHI }\end{array}$} & \multicolumn{3}{|c|}{ Univariable model } & \multicolumn{3}{|c|}{ Multivariable model $^{\mathrm{b}}$} \\
\hline & & $\overline{\mathrm{COR}}$ & (95\% Cl) & $P$ value & $\overline{\mathrm{aOR}}$ & $(95 \% \mathrm{Cl})$ & $P$ value \\
\hline Yes & 24.9 & 2.69 & $(1.75-4.12)$ & $<0.0005$ & 1.72 & $(1.06-2.81)$ & 0.028 \\
\hline No & 11.0 & 1.00 & Referent & & 1.00 & Referent & \\
\hline \multicolumn{8}{|l|}{ Type of sexual partners ${ }^{a}$} \\
\hline Regular only & 17.5 & 1.00 & Referent & & & & \\
\hline Regular and casual only & 21.5 & 1.30 & $(0.65-2.57)$ & 0.461 & & & \\
\hline Sex workers \& social escorts & 12.7 & 0.69 & $(0.31-1.52)$ & 0.355 & & & \\
\hline
\end{tabular}

cOR Crude odds ratio; $a O R$ Adjusted odds ratio

$R H I$ Recent HIV infection, RITA Recent infection testing algorithm; IDU Intravenous drug use

a Missing data were imputed

${ }^{b}$ Variables in the final multivariable logistic regression model were age at HIV diagnosis, year of HIV diagnosis, mode of detection, and whether the person had previous HIV test(s). Significant associations in the multivariable model were highlighted in bold

' Routine programmatic HIV screening includes screening programmes for persons with sexually transmitted infections, hospital inpatients and those identified through contact tracing

France [30] and Estonia [36]. The Singapore Health Promotion Board has been working with partner organizations to conduct programmes and campaigns targeted at high-risk individuals to urge them to go for regular HIV testing [47].

The HIV surveillance programmes in Singapore include anonymous testing, voluntary opt-out inpatient testing and antenatal screening. Table S2 shows the annual number of HIV tests and percentage tested positive for the three HIV surveillance programmes in 2013-2017. The proportion tested positive was highest at anonymous test sites compared with the other two HIV surveillance programmes, and it ranged from $1.0 \%$ (182 out of 17,781 tests done) in 2016 to $1.6 \%$ (227 out of 13,893 tests done) in 2013 [5]. Attendees at the Department of STI Control clinic, a specialist outpatient clinic for the diagnosis, treatment and control of STIs, constitute a sentinel population for unlinked HIV surveillance, and the HIV seroprevalence in this group ranged from $0.7 \%$ in 2013 to $1.5 \%$ in 2015 [5]. The surveillance of RHI is a useful additional tool to monitor ongoing HIV transmission in Singapore, as it sheds light on at-risk groups for which preventive efforts are targeted at. There have been several studies on late-stage HIV infection in Asian countries [8, 11], but estimation of the proportion of RHI was mostly limited to specific subpopulation groups such as MSM [40] and injecting drug users $[48,49]$. In Singapore, the independent risk factors for late presentation to HIV care included older age at diagnosis and HIV detection via medical care [8], which are in contrast to those of RHI in this study.

The findings of this study should be examined in the light of its limitations. The observational design of our study precluded causal inference. A limitation inherent to routine surveillance databases is the self-reporting of epidemiological information such as exposure risk factors and HIV testing history prior to positive diagnosis.
For newly-diagnosed HIV cases who had reported previous HIV test(s) prior to their positive diagnosis, we were unable to determine whether their infections were recently acquired as the date of their last negative HIV test was mostly unavailable. There may be additional unmeasured factors that could introduce confounding bias in our assessment of the association with RHI. As HIV diagnoses are subject to the number of persons tested and their testing patterns, there is a need to consider the estimated proportion of RHI in the context of frequencies of HIV testing and inter-test intervals in different subgroups [30, 50]. Although only $31.8 \%$ of all HIV cases notified to the National HIV Registry in 2013-2017 were included in this study, there were no major differences in the socio-demographic and epidemiological characteristics of those tested when compared with all the newlydiagnosed cases during the five-year period (Table 1).

Factors associated with misclassification by the BEDCEIA include long-term use of ART, low HIV viral load, and low CD4 cell count [51]. CD4 count can drop during sero-conversion [52], hence we might have slightly under-estimated the proportion of RHI for cases with CD4 count $<200$ cells $/ \mathrm{mm}^{3}$, as they would have been misclassified as NRHI according to the RITA in our study (Fig. 1). Nevertheless, the extent of misclassification was likely to be minimal with the use of the most widely used BED assay and additional consideration of clinical information. In addition to the use of BED-CEIA and false recency rate (FRR), other approaches such as antibody avidity tests or other detuned ELISA have been used in several studies to estimate recent infections alone or in combination [33, 34, 36, 38]. However, the principles of the three assays differ and the factors affecting FRR, as well as the window period during which the infection would be classified as recent, may also differ for each assay [20,38]. Dual testing algorithms have 
been shown to reduce FRR, even without correction for late stages of disease [53]. There is potential to improve the surveillance of RHI by implementing serological tests with higher sensitivity and specificity to achieve a more accurate proportion of recent infections among newlydiagnosed HIV cases.

In conclusion, approximately one-fifth of newly diagnosed cases were diagnosed early. As only a minority of HIV infections were diagnosed at the early stage of the disease, there is a pressing need to increase the level of awareness of HIV/AIDS and encourage more at-risk individuals to go for early and regular HIV testing. The strong associations observed between modifiable behaviors (voluntary testing and HIV testing history) and RHI highlight the importance of HIV prevention and control strategies that increase the accessibility to HIV testing for at-risk groups in order to reduce ongoing transmission risk.

\section{Abbreviations}

aOR: Adjusted odds ratio; AfA: Action for AIDS; ART: Antiretroviral therapy; BED-CEIA: Biotinylated peptide-capture enzyme immunoassay; $\mathrm{Cl}$ : Confidence interval; FRR: False recency rate; IDA: Infectious Diseases Act; IgG: Immunoglobulin; IQR: Interquartile range; MSM: Men having sex with men; NPHL: National Public Health Laboratory; NRHI: Non-recent HIV infection; RHI: Recent HIV infection; RITA: Recent infection testing algorithm; OD: Optical density; STIs: Sexually transmitted infections; WHO: World Health Organization

\section{Supplementary Information}

The online version contains supplementary material available at https://doi. org/10.1186/s12889-021-10478-5.

Additional file 1. Supplementary Tables S1 and S2. All supplementary

tables as listed in the article.

\section{Acknowledgments}

We thank the staff at the Singapore National HIV Registry for cross-matching the HIV epidemiological database and laboratory test results on recent infections, and providing the de-identified data for this study. We also thank Ms. Meng Li Teo and Ms. Yan Yan Liu for performing the laboratory tests and supporting logistical arrangements, and Dr. Lin Cui for overseeing operations at the National Public Health Laboratory. We acknowledge the contribution of the clinical and laboratory staff at Tan Tock Seng Hospital, Singapore General Hospital and National University Hospital in coordinating and providing samples to the National HIV Molecular Surveillance Programme.

\section{Authors' contributions}

LWA and CL conceived the study, participated in its design and coordination, and made contributions to the data acquisition and management. $\mathrm{CL}$ supervised the laboratory work and reporting of results, and described the laboratory methods for the study. LWA did statistical analysis and wrote the original draft. All authors (LWA, CL, CSW, ICB, MPHST, SA, VJML, YSL, AC, RTPL) were involved in revising the manuscript and approved the final manuscript.

\section{Funding}

This research did not receive any specific grant from funding agencies in the public, commercial, or not-for-profit sectors.

\section{Availability of data and materials}

The data that support the findings of this study are available from Li Wei Ang, National Public Health and Epidemiology Unit, National Centre for Infectious Diseases, but institutional restrictions apply to the availability of these data, which were used under license for the current study, and so are not publicly available.

\section{Declarations}

Ethics approval and consent to participate

Ethics approval for the study was obtained from the Domain Specific Review Board (DSRB) of National Healthcare Group, Singapore (2018/00959). The

DSRB gave waiver for informed consent, as the data was collected under the Infectious Diseases Act.

This study followed the reporting requirements of the Strengthening the Reporting of Observational Studies in Epidemiology (STROBE) Statement.

Consent for publication

Not applicable.

\section{Competing interests}

The authors have no competing interests to declare.

\section{Author details}

${ }^{1}$ National Public Health and Epidemiology Unit, National Centre for Infectious Diseases, 16 Jalan Tan Tock Seng, Singapore 308442, Singapore. ${ }^{2}$ National Public Health Laboratory, National Centre for Infectious Diseases, Singapore, Singapore. ${ }^{3}$ National HIV Programme, National Centre for Infectious Diseases, Singapore, Singapore. ${ }^{4}$ Department of Infectious Diseases, Tan Tock Seng Hospital, Singapore, Singapore. ${ }^{5}$ Yong Loo Lin School of Medicine, National University of Singapore, Singapore, Singapore. ${ }^{6}$ Saw Swee Hock School of Public Health, National University of Singapore, Singapore, Singapore. ${ }^{7}$ Division of Infectious Diseases, Department of Medicine, National University Hospital, National University Health System, Singapore, Singapore.

${ }^{8}$ Communicable Diseases Division, Ministry of Health, Singapore, Singapore. ${ }^{9}$ National Centre for Infectious Diseases, Singapore, Singapore. ${ }^{10}$ Lee Kong Chian School of Medicine, Nanyang Technological University, Singapore, Singapore. ${ }^{11}$ Department of Clinical Epidemiology, Office of Clinical Epidemiology, Analytics, and Knowledge (OCEAN), Tan Tock Seng Hospital, Singapore, Singapore. ${ }^{12}$ Department of Laboratory Medicine, National University Hospital, National University Health System, Singapore, Singapore.

Received: 1 December 2020 Accepted: 9 February 2021

Published online: 02 March 2021

\section{References}

1. Grinsztejn B, Hosseinipour MC, Ribaudo HJ, Swindells S, Eron J, Chen YQ, et al. Effects of early versus delayed initiation of antiretroviral treatment on clinical outcomes of HIV-1 infection: results from the phase 3 HPTN 052 randomised controlled trial. Lancet Infect Dis. 2014;14(4):281-90.

2. Maartens G, Celum C, Lewin SR. HIV infection: epidemiology, pathogenesis, treatment, and prevention. Lancet. 2014;384(9939):258-71.

3. Lundgren JD, Babiker AG, Gordin F, Emery S, Grund B, Sharma S, et al. Initiation of antiretroviral therapy in early asymptomatic HIV infection. N Engl J Med. 2015;373(9):795-807.

4. Günthard HF, Saag MS, Benson CA, del Rio C, Eron JJ, Gallant JE, et al. Antiretroviral drugs for treatment and prevention of HIV infection in adults: 2016 recommendations of the international antiviral society-USA panel. JAMA. 2016;316(2):191-210.

5. Ministry of Health, Singapore Communicable Diseases Surveillance in Singapore 2017. Communicable diseases division, Ministry of Health, Singapore, 2018. Available from: https://www.moh.gov.sg/resources-sta tistics/reports/communicable-diseases-surveillance-in-singapore-2017. Accessed 24 July 2018.

6. WHO Regional Office for South-East Asia. HIV/AIDS in the South-East Asia Region: progress report. Geneva: World Health Organisation; 2010. Available from: http://www.who.int/hiv/pub/surveillance/Searo_HIV-AIDS_HIV_report2 010_2.pdf. Accessed 24 July 2018.

7. Ho ZJM, Huang F, Wong CS, Chua L, Ma S, Chen Ml, et al. Using a HIV registry to develop accurate estimates for the HIV care cascade - the Singapore experience. J Int AIDS Soc. 2019;22(7):e25356.

8. Tey JS, Ang LW, Tay J, Cutter JL, James L, Chew SK, et al. Determinants of late-stage HIV disease at diagnosis in Singapore, 1996 to 2009. Ann Acad Med Singap. 2012;41(5):194-9. 
9. Adler A, Mounier-Jack S, Coker RJ. Late diagnosis of HIV in Europe: definitional and public health challenges. AIDS Care. 2009;21(3):284-93.

10. Antinori A, Coenen T, Costagiola D, Dedes N, Ellefson M, Gatell J. Et al; European late presenter consensus working group. Late presentation of HIV infection: a consensus definition. HIV Med. 2011;12(1):61-4.

11. Jeong SJ, Italiano C, Chaiwarith R, Ng OT, Vanar S, Jiamsakul A, et al. Late presentation into care of HIV disease and its associated factors in Asia: results of TAHOD. AIDS Res Hum Retrovir. 2016;32(3):255-61.

12. Mocroft A, Lundgren J, Antinori A, Ad M, Brännström J, Bonnet F, et al. Late presenters working group in COHERE in EuroCoord. Late presentation for HIV care across Europe: update from the Collaboration of Observational HIV Epidemiological Research Europe (COHERE) study, 2010 to 2013. Euro Surveill. 2015;20(47). https://doi.org/10.2807/1560-7917.ES.2015.20.47.30070.

13. Longo B, Pezzotti P, Boros S, Urciuoli R, Rezza G. Increasing proportion of late testers among AIDS cases in Italy, 1996-2002. AIDS Care. 2005;17(7):834-41.

14. Rosinska M, Janiec J, Niedźwiedzka-Stadnik M. Increase of new HIV diagnoses among men who have sex with men in Poland, 2000 to 2011. Euro Surveill. 2013;18(48):20642.

15. Dai SY, Liu JJ, Fan YG, Shan GS, Zhang HB, Li MQ, et al. Prevalence and factors associated with late HIV diagnosis. J Med Virol. 2015;87(6):970-7.

16. Widgren $\mathrm{K}$, Skar H, Berglund T, Kling AM, Tegnell A, Albert J. Delayed HIV diagnosis common in Sweden, 2003-2010. Scand J Infect Dis. 2014;46(12):862-7.

17. U.S. National Institutes of Health, Office of AIDS Research. Guidelines for the Use of Antiretroviral Agents in Adults and Adolescents Living with HIV. Last updated: December 18, 2019; Last reviewed: December 18, 2019. Available from: https://clinicalinfo.hiv.gov/en/guidelines/adult-and-adolescent-arv/ initiation-antiretroviral-therapy?view=full. Accessed 20 Sept 2020.

18. Ministry of Health, Singapore. Infectious Diseases Act. Available from: https://www.moh.gov.sg/policies-and-legislation/infectious-diseases-act. Accessed 31 Aug 2020

19. Parekh BS, Hanson DL, Hargrove J, Branson B, Green T, Dobbs T, Constantine N, Overbaugh J, McDougal JS. Determination of mean recency period for estimation of HIV type 1 incidence with the BED-capture EIA in persons infected with diverse subtypes. AIDS Res Hum Retrovir. 2011;27(3): 265-73.

20. Smoleń-Dzirba J, Wasik TJ. Current and future assays for identifying recent HIV infections at the population level. Med Sci Monit. 2011;17(5): RA124-33.

21. UNAIDS/WHO Working Group on Global HIV/AIDS and STI Surveillance. When and how to use assays for recent infection to estimate HIV incidence at a population level. Geneva: World Health Organization; 2011. Available from: http://www.who.int/diagnostics_laboratory/hiv_incidence_may13_fina I.pdf. Accessed 20 Sept 2020.

22. Sedia Biosciences Corporation. Sedia ${ }^{\mathrm{TM}}$ BED HIV-1 Incidence EIA. Enzyme immunoassay for population esitmates of HIV-1 incidence. Portland: Sedia Biosciences Corporation; 2014. Available from: https://sediabio.com/ products/bed-eia. Accessed 10 Oct 2019.

23. Parekh BS, Kennedy MS, Dobbs T, Pau CP, Byers R, Green T, et al. Quantitative detection of increasing HIV type 1 antibodies after seroconversion: a simple assay for detecting recent HIV infection and estimating incidence. AIDS Res Hum Retrovir. 2002:18(4):295-307.

24. Dobbs T, Kennedy S, Pau CP, McDougal JS, Parekh BS. Performance characteristics of the immunoglobulin G-capture BED-enzyme immunoassay, an assay to detect recent human immunodeficiency virus type 1 seroconversion. J Clin Microbiol. 2004;42(6):2623-8.

25. European Centre for Disease Prevention and Control. Monitoring recently acquired HIV infections in the European context. Stockholm: ECDC; 2013. Available from: https://www.ecdc.europa.eu/sites/portal/files/media/en/ publications/Publications/monitoring-recently-acquired-HIV-infectionseuropean-context.pdf. Accessed 20 Sept 2020

26. Stekhoven DJ, Buhlmann P. MissForest - non-parametric missing value imputation for mixed-type data. Bioinformatics. 2012;28(1):112-8.

27. Matsuokaa S, Nagashimab M, Sadamasub K, Moric H, Kawahatac T, Zaitsud S, et al. Estimating HIV-1 incidence in Japan from the proportion of recent infections. Prev Med Rep. 2019;16:100994.

28. Kao CF, Chang SY, Hsia KT, Chang FY, Yang CH, Liu HR, et al. Surveillance of HIV type 1 recent infection and molecular epidemiology among different risk behaviors between 2007 and 2009 after the HIV type 1 CRF07_BC outbreak in Taiwan. AIDS Res Hum Retrovir. 2011;27(7):745-9.

29. Kirby Institute. HIV in Australia: annual surveillance short report 2018. Sydney: Kirby Institute, UNSW Sydney; 2018. Available from: https://kirby.
unsw.edu.au/sites/default/files/kirby/report/supplHIV2018_content_2018092 Or.pdf. Accessed 20 Sept 2020

30. Aghaizu A, Murphy G, Tosswill J, DeAngelis D, Charlett A, Gill ON, et al. Recent infection testing algorithm (RITA) applied to new HIV diagnoses in England, Wales and Northern Ireland, 2009 to 2011. Euro Surveill. 2014;19(2).

31. Semaille C, Cazein F, Pillonel J, Lot F, Le Vu S, Pinget R, et al. Four years of surveillance of recent HIV infections at country level, France, mid 2003 2006: Experience and perspectives. Euro Surveill. 2008;13(36). pii: 18968.

32. Romero A, González V, Esteve A, Martró E, Matas L, Tural C. Et al; AERI study group. Identification of recent HIV-1 infection among newly diagnosed cases in Catalonia, Spain (2006-08). Eur J Pub Health. 2012;22(6):802-8.

33. Schüpbach J, Gebhardt MD, Tomasik Z, Niederhauser C, Yerly S, Bürgisser $P$, Matter L, Gorgievski M, Dubs R, Schultze D, Steffen I, Andreutti C, Martinetti G, Güntert B, Staub R, Daneel S, Vernazza P. Assessment of recent HIV-1 infection by a line immunoassay for HIV-1/2 confirmation. PLoS Med. 2007:4(12):e343.

34. Puchhammer-Stöckl E, Schmied B, Rieger A, Sarcletti M, Geit M, Zangerle R, et al. Low proportion of recent human immunodeficiency virus (HIV) infections among newly diagnosed cases of HIV infection as shown by the presence of HIV-specific antibodies of low avidity. J Clin Microbiol. 2005;43(1):497-8.

35. Hofmann A, Hauser A, Zimmermann R, Santos-Hövener C, BätzingFeigenbaum J, Wildner $S$, et al. Surveillance of recent HIV infections among newly diagnosed HIV cases in Germany between 2008 and 2014. BMC Infect Dis. 2017;17(1):484.

36. Soodla P, Simmons R, Huik K, Pauskar M, Jögeda EL, Rajasaar H. Et al; concerted action on SeroConversion to AIDS and death in Europe (CASCADE) collaboration in EuroCoord. HIV incidence in the Estonian population in 2013 determined using the HIV-1 limiting antigen avidity assay. HIV Med. 2018;19(1):33-41.

37. Nozza S, Cozzi-Lepri A, Bai F, Rusconi S, Gori A, Cinque P, et al. Proportion and factors associated with recent HIV infection in a cohort of patients seen for care in Italy over 1996-2014: data from the ICONA Foundation study cohort. PLoS One. 2017;12(12):e0189045.

38. Rosińska M, Marzec-Bogustawska A, Janiec J, Smoleń-Dzirba J, Wąsik T, Gniewosz J, et al. CASCADE collaboration in eurocoord. High percentage of recent HIV infection among HIV-positive individuals newly diagnosed at voluntary counseling and testing sites in Poland. AIDS Res Hum Retroviruses. 2013:29(5):805-13.

39. Schwarcz S, Weinstock H, Louie B, Kellogg T, Douglas J, Lalota M, et al. Characteristics of persons with recently acquired HIV infection: application of the serologic testing algorithm for recent HIV seroconversion in 10 US cities. J Acquir Immune Defic Syndr. 2007:44(1):112-5.

40. Xu JJ, Tang WM, Zou HC, Mahapatra T, Hu QH, Fu GF, et al. high HIV incidence epidemic among men who have sex with men in China: results from a multi-site cross-sectional study. Infect Dis Poverty. 2016;5(1):82.

41. Medland NA, Nicholson S, Chow EPF, Read TRH, Bradshaw CS, Denham I, et al. Time from HIV infection to virological suppression: dramatic fall from 2007 to 2016. AIDS. 2017;31(17):2377-85.

42. Action for AIDS, Singapore. Press Room: MSM Outreach HIV Testing Project Round 6 (2013). Available from: https://afa.org.sg/portfolio-item/msm-outrea ch-hiv-testing-project-round-6/. Accessed 20 Sept 2020.

43. Fisher M, Pao D, Murphy G, Dean G, McElborough D, Homer G, Parry JV. Serological testing algorithm shows rising HIV incidence in a UK cohort of men who have sex with men: 10 years application. AIDS. 2007;21(17):2309-14.

44. Bätzing-Feigenbaum J, Loschen S, Gohlke-Micknis S, Hintsche B, Rausch M, Hillenbrand $H$, et al. Implications of and perspectives on HIV surveillance using a serological method to measure recent HIV infections in newly diagnosed individuals: results from a pilot study in Berlin, Germany, in 2005-2007. HIV Med. 2009;10(4):209-18

45. Action for AIDS, Singapore. Annual Report 2018. Available from: https:/afa.org. sg/portfolio-item/annual-report-statement-2018/. Accessed 7 Sept 2019.

46. Ang LW, Tey SH, James L. HIV-positive cases detected during medical care versus voluntary HIV screening in Singapore - how are they different? Singapore Epidemiol News Bull. 2009;35(3):52-6.

47. Ministry of Health, Singapore. Ministry of Health and Health Promotion Board Urge At-Risk Groups to go for Regular HIV Testing. Press Releases: 1 December 2017. Available from: https://www.moh.gov.sg/news-highlights/ details/ministry-of-health-and-health-promotion-board-urge-at-risk-groupsto-go-for-regular-hiv-testing-2018. Accessed 20 Sept 2020.

48. Hu DJ, Vanichseni S, Mock PA, et al. HIV type 1 incidence estimates by detection of recent infection from a cross-sectional sampling of injection drug users in Bangkok: use of the lgG capture BED enzyme immunoassay. AIDS Res Hum Retrovir. 2003;19(9):727-30. 
49. Jiang $\mathrm{Y}$, Wang $\mathrm{M}$, Ni M, et al. HIV-1 incidence estimates using lgG-capture BED-enzyme immunoassay from surveillance sites of injection drug users in three cities of China. AIDS. 2007;21(suppl 8):S47-51.

50. Remis RS, Palmer RW. Testing bias in calculating HIV incidence from the serologic testing algorithm for recent HIV seroconversion. AIDS. 2009;23(4): 493-503.

51. Laeyendecker O, Brookmeyer R, Oliver AE, Mullis CE, Eaton KP, Mueller AC. Et al; multicenter Aids cohort study macs. Factors associated with incorrect identification of recent HIV infection using the BED capture immunoassay. AIDS Res Hum Retrovir. 2012;28(8):816-22.

52. Lodi S, Phillips A, Touloumi G, Geskus R, Meyer L, Thiébaut R. Et al; CASC ADE collaboration in EuroCoord. Time from human immunodeficiency virus seroconversion to reaching CD4+ cell count thresholds $<200,<350$, and $<$ 500 cells $/ \mathrm{mm}^{3}$ : assessment of need following changes in treatment guidelines. Clin Infect Dis. 2011:53(8):817-25.

53. Braunstein SL, Nash D, Kim AA, Ford K, Mwambarangwe L, Ingabire CM, et al. Dual testing algorithm of BED-CEIA and AxSYM avidity index assays. performs best in identifying recent HIV infection in a sample of Rwandan sex workers. PLoS One. 2011;6(4):e18402.

\section{Publisher's Note}

Springer Nature remains neutral with regard to jurisdictional claims in published maps and institutional affiliations.

Ready to submit your research? Choose BMC and benefit from:

- fast, convenient online submission

- thorough peer review by experienced researchers in your field

- rapid publication on acceptance

- support for research data, including large and complex data types

- gold Open Access which fosters wider collaboration and increased citations

- maximum visibility for your research: over $100 \mathrm{M}$ website views per year

At $\mathrm{BMC}$, research is always in progress.

Learn more biomedcentral.com/submissions 